\title{
Pedagogia universitária - Valorizando o ensino e a docência na universidade
}

\author{
Maria Isabel de Almeidai \& Selma Garrido Pimentaii \\ Universidade de São Paulo, Brasil
}

\begin{abstract}
Resumo
Como e em que circunstâncias processos de formação relativos ao saber ser professor podem ser desenvolvidos em uma universidade complexa? O texto aponta possíveis respostas a essa questão, a partir da análise da constituição de uma política de formação dos docentes em uma universidade pública Universidade de São Paulo, Brasil -, cuja tradição das atividades de pesquisa se sobrepõe às de ensino. Para ampliar a compreensão da experiência empreendida, discute o significado do ensino de graduação no contexto da crise da universidade contemporânea e aponta a relevância dos docentes para assegurar o significado social da universidade. Teve como instrumentos que sustentam a análise os registros escritos e as pesquisas produzidas pelos participantes do processo (docentes, gestores, doutorandos). Considerando o marco teórico-conceitual sobre docência universitária, os resultados da análise apontam algumas contribuições para a área: a importância do enraizamento institucional de políticas de formação pedagógica de docentes universitários; a inserção destas no orçamento institucional; a diversidade de ações formativas; e a valorização da produção científica dos docentes sobre ensino.
\end{abstract}

Palavras-chave

Docência e pesquisa na graduação; Universidade; Política institucional

\section{Introdução}

Em decorrência da importância do ensino nos cursos de graduação e o frequente despreparo dos docentes para essa atividade, a formação de 
Maria Isabel de Almeida \& Selma Garrido Pimenta

professores para o ensino superior vem ganhando relevância no cenário mundial. Pesquisas e experiências institucionais têm sido objeto de análises em congressos científicos. O presente texto traz contribuições ao debate a partir das intersecções de nossas pesquisas e da coordenação de uma experiência realizada no âmbito da Universidade de São Paulo, Brasil. Seus objetivos são discutir como se forma o professor universitário para atuar concomitantemente nas atividades de investigação e produção do conhecimento e nas atividades de ensino. Para isso, debate as compreensões conceituais, metodológicas e organizacionais da formação dos docentes universitários. Espera-se, assim, contribuir para o incremento de políticas institucionais de formação contínua capazes de superar os limites de ações isoladas como cursos, seminários, disciplinas de pós-graduação, palestras e estágios que têm marcado a preparação desses professores.

Entendendo que políticas para essa formação devam se enraizar nos contextos sociais, econômicos e culturais que envolvem a trajetória da universidade contemporânea, o texto discute também aspectos relativos às transformações da universidade e às características e novas demandas que os diversos perfis de estudantes colocam para a formação do docente do ensino superior. Trataremos, em síntese, dos aspectos que ajudam a explicar as razões da crescente importância da formação dos docentes universitários, na perspectiva de se produzir mudanças em suas práticas, e as repercussões dessa tendência na implementação de políticas institucionais focadas na valorização e qualificação do trabalho docente.

A universidade é uma instituição educativa cuja finalidade é o permanente exercício da crítica, que se sustenta na pesquisa, no ensino e na extensão, ou seja, a produção do conhecimento a partir da problematização dos conhecimentos historicamente produzidos e de seus resultados na construção da sociedade humana e dos novos desafios e demandas que esta coloca. Esses desafios são produzidos e identificados inclusive nas análises que se realizam no processo de ensinar, na experimentação e na análise dos projetos de extensão, por meio das relações que são estabelecidas entre os sujeitos e os objetos de conhecimento.

Como afirma Morin (2000),

a universidade conserva, memoriza, integra e ritualiza uma herança cultural de saberes, ideias e valores que acaba por ter um efeito regenerador, porque a 
universidade se incumbe de reexaminá-la, atualizá-la e transmiti-la [ao mesmo tempo em que] gera saberes, ideias e valores que, posteriormente, farão parte dessa mesma herança (p. 15).

A universidade tem, portanto, uma função transecular, que vai do passado ao futuro por intermédio da crítica ao presente, com vistas a humanizar a sociedade. Desse modo, o sentido da educação é o de possibilitar que todos os seres humanos tenham as condições de serem partícipes e desfrutadores dos avanços da civilização historicamente construída e responsáveis pela formulação de propostas criativas, visando à superação dos danos causados por essa mesma civilização (Freire, 2011).

$\mathrm{Na}$ sociedade contemporânea, o ensino de graduação encontra-se fortemente submetido à lógica do mercado e do consumo, configurando o que alguns autores denominam de processo de fastfoodização da universidade (Debry, Leclercq, \& Boxus, 1998), configurando-se como uma imensa usina de produção, em que os estudantes são considerados apenas elos do sistema no qual a aprendizagem é rápida e ligeira, exigindo apenas o suficiente para se obter créditos e diplomas. Nessa lógica, o percurso formativo é como um supermercado no qual as disciplinas estão dispostas em gôndolas, à escolha do estudante, e disponibilizadas conforme a decisão individual dos docentes ou departamentos. A carreira acadêmica destes (publicar muito e o mais rápido possível) tem primazia em relação à formação dos estudantes, e as culturas da academia e dos jovens ficam separadas por um fosso intransponível.

Concordando com essa crítica, entendemos que é preciso criar uma nova cultura acadêmica nos cursos de graduação: que considere o direito do estudante de desenvolver uma postura frente ao saber que supere a especialização estreita; que problematize as informações e garanta sua formação como cidadão e profissional cientista compromissado com a aplicação do conhecimento em prol da melhoria da qualidade de vida de toda a sociedade; que possibilite o desenvolvimento do pensamento autônomo, substituindo a simples transmissão do conhecimento pelo engajamento dos estudantes num processo que lhes permita interrogar o conhecimento elaborado, pensar e pensar criticamente; que enseje a resolução de problemas, estimule a discussão, desenvolva metodologias de busca e de construção de conhecimentos (ensinar com pesquisa); que confronte os 
conhecimentos elaborados e as pesquisas com a realidade; que mobilize visões inter e transdisciplinares sobre os fenômenos; que aponte soluções aos problemas sociais (ensinar com extensão); e que crie uma nova cultura acadêmica que valorize o trabalho dos docentes na graduação.

Ensinar na universidade de modo a formar alunos com essas características aponta para uma ação docente diferenciada da tradicionalmente praticada. Como um profissional que realiza um serviço à sociedade, o professor universitário atua de forma reflexiva, crítica e competente no âmbito de sua disciplina, explicitando seu sentido, seu significado e sua contribuição no percurso formativo dos estudantes, inserida no projeto político-pedagógico dos cursos, vivenciado no cotidiano do ensino e da pesquisa. Os cursos, por sua vez, inserem-se no projeto políticopedagógico-institucional com suas identidades próprias, considerando as demandas da sociedade contemporânea em geral e no contexto do campo de ação próprio das áreas de saber envolvidas. Nesse sentido, é oportuna a contribuição do Fórum Nacional de Pró-Reitores de Graduação das Universidades Brasileiras (Dias, 2007):

Como todo saber e todo exercício profissional ocorrem em situações sóciohumanas concretas que requerem mudanças profundas, todo Projeto Pedagógico deve pautar-se em uma visão de mundo cultivada com racionalidade ética. Esta visão de mundo constitui-se em horizonte daquilo que se "pro-jeta" e ponto de referência de todas as ações e decisões do curso (p. 12).

Considerando as proposições aqui ensejadas, o estudo em questão busca apontar possibilidades de formação pedagógica de docentes como meio de valorizar o ensino de graduação a partir da experiência realizada na Universidade de São Paulo (USP) ${ }^{1}$, ressaltando os modos organizacionais que possibilitaram o seu enraizamento na cultura institucional acerca da importância da formação para a docência.

\section{Marco teórico-conceitual da formação docente}

Como fazer frente aos novos desafios, trazidos pelas mudanças sociais, ao trabalho de formação dos estudantes universitários, considerando o equilíbrio e a convergência entre a pesquisa nas áreas específicas e na área pedagógica na atuação dos docentes? Considerando essa questão, 
discutiremos os pressupostos conceituais e metodológicos que têm embasado a proposição de políticas institucionais para a formação de docentes no ensino superior.

A literatura sobre o tema (Almeida, 1999, 2006, 2012; Araújo, 2005; Benedito et al., 1995; Cunha, 1998; Leite, 1999; Nóvoa, 2013; Pimenta \& Anastasiou, 2002; Veiga \& Castanho, 2000; Zabalza, 2004) discute a característica que identifica o professor do ensino superior como aquele que domina o conhecimento específico de sua área ou disciplina, mas que não necessariamente sabe ensinar, o que, em geral, não the foi exigido nas instituições nem mesmo no âmbito das políticas educacionais. Estas, quando muito, apontam tímida e genericamente que devem ser preparados para ensinar. Ao contrário, do professor da escola básica, exige-se a formação de nível superior com a comprovação de inúmeras horas dedicadas a aprendizados didáticos, avaliativos e organizacionais do ensino. Paradoxalmente, aos docentes dos cursos superiores que formam professores para a escola básica não é exigida a competência acadêmica para ensinar. E paradoxal ainda é a exigência de uma prova didática na maioria dos concursos para ingresso na carreira docente do ensino superior, que raramente examina devidamente a competência didática para o ensino nos cursos de graduação.

Estudos na área (Pimenta \& Anastasiou, 2002; Zabalza, 2004; Biggs, 2006; Flores, 2007; Rué, 2007; Cunha, 2009; Rios, 2009; Leite \& Ramos, 2012; Almeida, 2012, dentre outros) mostram que a preparação de docentes para a vida acadêmica, como especialistas em um campo específico do conhecimento, ocorre em geral em programas de pós-graduação stricto sensu, nos quais o futuro docente desenvolve os conhecimentos teóricos e instrumentais da atividade de pesquisa e consolida as apropriações referentes ao seu campo científico de atuação. Desenvolve-se, nesses programas, a preparação profissional voltada para as atividades de pesquisa e de produção do conhecimento, que se complementam com a etapa da divulgação dos resultados em eventos e em publicações e conferem visibilidade e status ao pesquisador. Outras atividades, também de grande relevância acadêmica, como a orientação de outros pesquisadores ou aquelas voltadas para a aferição da qualidade das pesquisas realizadas pelos pares, como bancas ou pareceres, são entendidas como decorrentes das competências do 
pesquisador. Entretanto, sua formação para a docência praticamente inexiste nos cursos de pós-graduação. Cunha (2006) mostra que "a formação do professor universitário tem sido entendida, por força da tradição e ratificada pela legislação, como atinente quase que exclusivamente aos saberes do conteúdo de ensino" (p. 258), colocando o ensino como uma decorrência das demais atividades. $O$ que se constata então é que o professor universitário não tem uma formação voltada para os processos de ensino e aprendizagem pelos quais é responsável quando inicia sua vida acadêmica. Os elementos constitutivos de sua atuação docente, como relação da disciplina com o projeto do curso, planejamento, organização da aula, metodologias e estratégias didáticas, avaliação, peculiaridades da interação professor-aluno, Ihe são desconhecidos, bem como a compreensão do sentido e do significado de sua área específica na formação dos estudantes como sujeitos e cidadãos, questões essas determinantes do que se ensina, do para que se ensina e dos modos como se ensina e que são próprias da atividade educativa de ensinar.

Pesquisas em diferentes países (DiPietro \& Buddie, 2013; Kato, 2013; Creten \& Huyghe, 2013; Rué et al., 2013) mostram que predomina, dentre os docentes do ensino superior, um despreparo e até um desconhecimento científico do que seja o processo de ensino e de aprendizagem pelo qual serão responsáveis a partir do instante em que ingressam no departamento e na sala de aula. Considerando os problemas que esse desconhecimento acarreta na formação dos estudantes de graduação, observa-se nesse campo de pesquisa um crescimento da preocupação com a formação e o desenvolvimento profissional de professores universitários e com as inovações no campo da atuação didática.

O conjunto de ações que caracteriza a docência universitária pressupõe elementos de várias naturezas, o que coloca aos sujeitos por ela responsáveis um rol de demandas, contribuindo para configurá-la como um campo complexo de ação. Cunha (2009) e Almeida (2012) apontam, o que podemos sintetizar, três dimensões da formação docente: a dimensão profissional, na qual se aninham os elementos definidores da atuação como a incessante construção da identidade profissional, as bases da formação (inicial ou contínua) e as exigências profissionais; a dimensão pessoal, na qual há que se desenvolver as relações de envolvimento e compromisso com a docência, bem como a compreensão das circunstâncias de realização do 
trabalho e dos fenômenos que afetam os envolvidos com a profissão e os mecanismos para se lidar com eles ao longo da carreira; e a dimensão organizacional, na qual são estabelecidas as condições de viabilização do trabalho e os padrões a serem atingidos na atuação profissional. Esse movimento configura o que se pode denominar de uma concepção ecológica da formação docente, que sustenta a necessidade de se formar um professor capaz de desenvolver uma cultura profissional que the assegure a possibilidade de ser, individual e coletivamente, um agente de mudança que consiga enfrentar situações problemáticas contextualizadas, em meio às quais ele saiba não só o que fazer e como fazer, mas também porque e para que fazê-lo.

Compreende-se ainda que a formação do professor necessita ser aninhada numa perspectiva de desenvolvimento profissional (Almeida, 2012), que tem na formação inicial o princípio de um processo contínuo no qual a profissão se desenvolve por meio de descobertas individuais e coletivas, que se sedimentam e se reconstroem apoiadas em rigorosa reflexão sobre a prática, mediada pela teoria, o que permite a reconstrução da experiência na perspectiva do aprimoramento da atuação futura. Portanto, a interação com 0 contexto de atuação constitui elemento essencial ao processo de formação ao longo da carreira docente.

Como a qualidade da formação propiciada aos estudantes é elemento que confere reconhecimento institucional, entendemos que, para viabilizá-la como fruto da ação coletiva de seus docentes, a formação se constitui em elemento de valorização do trabalho docente e pressupõe que os professores sejam capazes de considerar, numa perspectiva crítica, os contextos histórico, social, cultural e organizacional onde realizam suas práticas.

Assim, com base em estudos da área (Brezinski, 2002; Alarcão, 2003; Benedito et al., 1995; Masetto, 2004; Zabalza, 2004; Fiorentini \& Souza e Melo, 1998), entendemos que o ensino é uma atividade que requer conhecimentos específicos, consolidados por meio de formação voltada especialmente para esse fim, bem como atualização constante das abordagens dos conteúdos e das novas maneiras de ensiná-los. A mediação da prática coloca-se como indispensável; porém, em estreita articulação com a teoria e ancorada na reflexão, como processo que busca atribuir sentido àquilo que se pratica. 
As novas demandas sociais, postas para a formação de futuros profissionais, trazem como decorrência a necessidade de se processar profunda renovação no contexto da sala de aula e nas metodologias de ensino universitário, o que coloca implicações novas para os docentes em seu trabalho formativo. Considerando que os enfoques didáticos clássicos, centrados na aula e na atuação do professor, vêm cedendo espaço a modos de ensino centrados em atividades a serem exercidas pelos estudantes de maneira autônoma, configurar novos modos de planejar e executar o processo de ensino-aprendizagem constitui uma demanda central da formação nesse novo contexto. Trata-se, portanto, de propiciar condições formativas para que se desenvolva uma mudança de paradigma orientador desse processo, o que requer a definição de organizações curriculares baseadas em lógicas interdisciplinares, reorientação nos objetivos, na metodologia docente, nas estratégias de ensino-aprendizagem, nos sistemas de avaliação, na organização dos recursos e nos espaços de trabalho. Nesse redesenho nos planos de estudos, a literatura na área aponta novas novas capacidades para os docentes, de modo a favorecer o desenvolvimento de outras dimensões na formação dos alunos. Trata-se, portanto, da necessidade de constituição de um novo paradigma de docência universitária.

Feixas (2004) considera que o apoio departamental, a colaboração entre os pares e as atividades de formação são essenciais para que os docentes possam mudar suas concepções, de modo a compreender o ensino como possibilidade de o estudante desenvolver e transformar suas próprias ideias a respeito da disciplina e sua relação com o conhecimento, o campo profissional e a sociedade. Ainda Feixas (2004), analisando universidades espanholas, afirma que a formação dos docentes está presente hoje em todas estas e que a adesão voluntária dos docentes às atividades de formação constitui um fator que favorece o aperfeiçoamento da ação docente. No Brasil, os programas existentes confirmam essa evidência no que se refere à adesão voluntária, especialmente nas universidades públicas, onde as condições de vínculo empregatício propiciam estabilidade e permanência no quadro docente. Já nas particulares, em geral, a permanência no quadro docente é vinculada às avaliações que os estudantes fazem sobre o trabalho dos professores em sala se aula e, muitas vezes, são as mesmas utilizadas para dispensar professores. Assim, os programas de formação docente tendem a 
ser de participação obrigatória, o que nem sempre resulta em qualidade formativa.

A formação dos docentes do ensino superior é um campo das políticas institucionais que requer atenção especial. Nogueira (cit. por Feixas, 2004) pontua sua enorme importância:

Tanto a formação pedagógica inicial como o desenvolvimento profissional do professorado universitário requer uma política global da universidade que dignifique e valorize as funções docentes como fundamentais para se alcançar a "excelência". Só quando se gera um clima no qual a alta qualificação na docência seja um indicador mais valorizado que os resultados de uma pesquisa ou o custo, às vezes desproporcional, de aparatos de infraestrutura, será possível estimular a autorreflexão sobre o fazer docente e a implicação dos professores da educação superior em programas de formação pedagógica ( $\mathrm{p}$. 41).

Nas experiências espanhola e brasileira, conforme Almeida (2012), encontramos aproximações no que se refere ao desafio para as instituições de formar o conjunto de seus docentes, envolvendo aqueles professores que não sentem necessidade de se aperfeiçoar profissionalmente na ação de ensinar. Em suas políticas de qualidade para o desenvolvimento profissional docente, têm sido consideradas: as necessidades pessoais e coletivas que são focadas em coletivos com características similares, como, por exemplo, docentes jovens ou que estão em início de carreira, docentes em etapas avançadas, coordenadores de cursos, responsáveis pelo ensino de graduação, chefes ou dirigentes; e a definição de diretrizes políticas que articulam a promoção na carreira com os esforços empreendidos para a melhoria da docência, desenvolvimento de inovações no ensino e valorização da produção de conhecimento sobre o ensino (pesquisas sobre o ensino). As conclusões das análises sobre essas experiências recomendam que as políticas de avaliação do professorado sejam definidas em estreita articulação com a política de formação docente, voltadas para a valorização e a estabilidade profissional.

Para finalizar essas considerações, valemo-nos das recomendações de Fernández (1999) ao propor alguns indicadores para a organização de uma política de formação docente institucional: compromisso das instituições universitárias para criar as condições que tornem possível esse processo; determinação em caminhar rumo a uma cultura de colaboração; concepção 
de formação ligada à prática docente e que compreenda a inovação e a formação como elementos complementares da organização da política formativa; apostar em ações que tenham relação com a qualidade da docência, potencializando e gerando interesses pela melhora do ensino; gerar os elementos condicionantes capazes de integrar em uma mesma política as atuações sobre avaliação, desenvolvimento profissional e inovação. Com isso, argumentamos em favor de uma real valorização do empenho na formulação de políticas institucionais de formação, estáveis e permanentes, voltadas para o aprimoramento da atividade de ensinar, compreendida como um dos componentes essenciais para assegurar a qualidade do trabalho na universidade contemporânea.

\section{Uma experiência de valorização da docência no ensino superior: Desafios e contribuições}

Como e em quais circunstâncias os processos de formação relativos ao ser e ao saber ser professor universitário podem ser desenvolvidos e potencializados? Na busca de respostas a essa questão, apresentamos, a seguir, a análise da política de valorização e formação de docentes que desenvolvemos na Universidade de São Paulo (USP), cuja tradição das atividades de pesquisa se sobrepõe às de ensino. Sua implementação foi uma iniciativa da Pró-Reitoria de Graduação, na qual ocupamos os cargos de próreitora e de assessora especializada.

Nessa condição, definimos como principais três grandes diretrizes: valorizar o ensino de graduação no que se refere à qualidade formativa dos discentes e às condições da docência; a inclusão social de estudantes egressos de escolas públicas; e a ampliação de vagas. Constitui objeto deste texto a análise da primeira delas - valorizar o ensino de graduação -, que foi traduzida nos seguintes eixos programáticos: a) apoiar propostas e programas para experimentação de novas formas de organização curricular e de novos modos de ensinar na universidade; de organização departamental e não departamental; de novos modelos pedagógicos para o ensino noturno e para o ensino presencial, com apoio às relações midiáticas professor/aluno/turmas; b) apoiar o desenvolvimento profissional e acadêmico de docentes; c) apoiar a implementação dos Grupos de Apoio Pedagógico (GAPs). Esses eixos expressam o compromisso da gestão da Universidade 
com a necessidade de encontrar estratégias capazes de promover mudanças e melhoras na qualidade da docência e do ensino de graduação.

As linhas de ação foram formuladas com vistas aos objetivos anteriormente explicitados e de modo a oferecer condições para que se superasse a fragmentação das múltiplas atividades da vida profissional dos docentes, intensificada nos últimos anos de modo exacerbado, com predomínio daquelas voltadas para a pesquisa em detrimento das centradas no ensino, o que estimula a desvalorização do empenho e do tempo docente a ele dedicado. Também se buscou criar, dentre os docentes em formação, uma base político-pedagógica capaz de permitir redirecionamentos no trato com os conhecimentos científicos, nos modos organizativos do currículo e das abordagens de ensino, nas relações interativas com os estudantes e nas formulações das ações institucionais. Para tanto, partimos do estudo crítico dos problemas acadêmicos e dos referenciais teóricos e metodológicos que permitissem a elaboração de respostas centradas no desenvolvimento dos professores, com vistas a uma educação e a um ensino emancipatórios. As ações visavam não apenas um domínio de conhecimentos básicos para o trabalho em sala de aula, expectativa primeira dos docentes, mas que compreendessem a docência de cada um como expressão de compromissos científicos, éticos e políticos do ensino de graduação em uma universidade pública.

Diversos caminhos institucionais foram explorados com vistas a avançar na valorização do ensino de graduação e das condições da docência. Um primeiro refere-se à formulação de indicadores para a avaliação do trabalho docente encaminhados à Comissão Especial de Regime de Trabalho (CERT), órgão responsável pela avaliação institucional docente na Universidade nos âmbitos do ensino, da pesquisa e da extensão. Diante da evidência de que critérios externos de avaliação utilizados mundialmente e impetrados pelas agências de fomento foram sendo incorporados gradativamente na universidade em estudo, observou-se que as atividades de ensino na graduação foram perdendo importância frente às ligadas à pesquisa, configurando uma quase total desvalorização da docência. Esse fenômeno é apontado por Gibbs (2004), que diagnostica as consequências desse movimento: 
Cada hora adicional de esforço que um professor dedica à docência provavelmente reduz uma hora de esforço que dedicaria à pesquisa e isso prejudica suas expectativas de carreira e sua remuneração, a longo prazo. Há uma quase perfeita correlação negativa entre as horas de docência e o salário. Os sistemas de reconhecimento e recompensa habitualmente desanimam os professores de levarem a sério a docência (p. 16).

Identificado esse problema, abriu-se um processo de discussão nas unidades da Universidade que resultou na proposição de 19 novos itens de valorização do trabalho dos docentes no ensino de graduação, o que possibilitou requalificar os critérios de avaliação das atividades de ensino no âmbito da vida acadêmica, dando-se maior destaque às ações destinadas à docência no contexto da carreira docente.

Um segundo caminho bastante significativo para a valorização do ensino de graduação foi a criação do Programa Ensinar com Pesquisa, que disponibilizou 800 bolsas de estudos a estudantes interessados em desenvolver pesquisas relativas aos processos de ensino do seu curso com orientação de um docente responsável. Constituído com recursos orçamentários da Universidade, o Programa teve como intenção primeira fomentar a aproximação entre as práticas de ensinar e a pesquisa no e sobre o ensino. O pressuposto teórico que o sustenta é o de que o ensino e a aprendizagem que consideram a pesquisa como parte de seus elementos constitutivos resultam em uma formação de qualidade científica e social dos estudantes de graduação. No período da gestão (2006-2009), foram apoiados 2600 projetos.

Um terceiro caminho foi a criação do Curso de Pedagogia Universitária e dos Seminários de Pedagogia Universitária, ambos tendo por característica a adesão espontânea dos docentes. Os cursos contaram com a participação de $10 \%$ (600) do total de docentes no período da gestão. Voltado para a formação pedagógica, o Curso de Pedagogia Universitária teve duração anual e carga de 240 horas e se configurou como de especialização. Os Seminários de Pedagogia Universitária, realizados mensalmente com a participação de pesquisadores renomados do Brasil, Espanha, Argentina e Portugal, abordaram temas relativos à análise do contexto sociocultural no qual a universidade está envolvida, aos conhecimentos pedagógicos pertinentes ao ensino, às condições institucionais e de trabalho que permeiam o fazer docente, além de oferecerem uma visão de como a questão da docência universitária tem merecido destaque nesses países. 
Com essas iniciativas configurando uma política articulada de valorização da docência, a Pró-Reitoria de Graduação teve por meta superar as ações pontuais do tipo simpósios, seminários, palestras ou oficinas, presentes na cultura institucional, e que, embora sejam iniciativas para melhorar a qualidade da docência, são, em geral, ações fragmentadas e descontínuas e com foco nos docentes e seu ensino de modo individual. Conforme aponta Gibbs (2004), com as pressões e demandas postas às universidades, decorrentes das transformações socioeconômicas das últimas décadas, foi-se tornando evidente que é preciso ir além de ações pontuais, que promovem mudanças modestas e localizadas, para que as possíveis respostas ou propostas pedagógicas possuam profundidade e abrangência compatíveis com o novo quadro instalado nos mais diferentes cursos.

A política que empreendemos (Pimenta, Almeida, \& Oliveira, 2010) possibilitou a abertura de caminhos institucionais de formação docente com caráter mais duradouro e contínuo no âmbito da Universidade de São Paulo. Essa experiência foi desenvolvida com a preocupação de se produzir dados e referenciais que possibilitassem sua análise posterior. Assim, os registros escritos e as avaliações geradas no cotidiano das ações formativas foram os instrumentos utilizados no presente estudo, dentre os quais destacamos: a produção escrita dos docentes participantes dos cursos; a sistematização e análise do processo realizada pelos coordenadores dos GAPs (Corrêa, 2011); a sistematização e análise da experiência elaborada pela docente responsável pelos cursos (Anastasiou, 2011); as pesquisas produzidas por doutorandas que acompanharam o processo (Belletati, 2011; Faria, 2011); e o estudo comparativo da experiência uspiana com algumas espanholas, realizado em pesquisa de pós-doutoramento (Almeida, 2012).

\section{Alguns resultados da experiência da USP}

Destacaremos neste texto os principais resultados gerados no âmbito macroinstitucional. As mudanças no âmbito dos cursos e das práticas docentes estão sendo objeto de pesquisas em desenvolvimento.

As mudanças nas culturas institucionais e, em especial, em culturas tradicionais e fortemente arraigadas, como no caso, em geral, não são percebidas a curto prazo. Entretanto, para que as alterações se consolidem 
no médio e longo prazo, as ações precisam ser enraizadas no solo revolvido do presente. Assim, uma de nossas preocupações centrais foi a de situar a política de valorização docente no contexto das ações que já existiam, ainda que fragmentadas e esparsas, com vistas a potencializar os caminhos já trilhados, além de instituir os novos programas. No primeiro caso, destacamse as ações dos GAPs, criados em 2004 por docentes interessados e voluntariamente organizados nas faculdades e institutos, com o objetivo de oferecer apoio pedagógico às atividades docentes. A partir desses GAPs locais, foi constituído o GAP Central no âmbito da Pró-Reitoria de Graduação, composto por um representante de cada GAP local, tendo por função organizar ações mais amplas e suportadas institucionalmente. As ações em curso desses grupos ofereceram, quando do início de nossa gestão, as referências para a proposição de um plano de atuação nos marcos da pedagogia universitária. Redirecionámos a estrutura, destinando ao GAP Central a coordenação dos Cursos de Pedagogia Universitária, disponibilizando recursos e pessoal de apoio e para a contratação de professora especializada em processos formativos de docente do ensino superior e com experiência reconhecida e valorizada nacionalmente.

Em meio às mudanças de grande porte na Universidade, expressas na política da gestão que se iniciava ${ }^{2}$, o que se pretendeu foi fortalecer uma concepção mais dinâmica de desenvolvimento acadêmico, cujas respostas para elevar o patamar qualitativo da formação dos estudantes passassem a ser discutidas e propostas no âmbito das unidades de ensino e de pesquisa. Investiu-se, então, na constituição e no fortalecimento das bases pedagógicas dos docentes participantes para que fossem ampliadas suas possibilidades de análise dos problemas acadêmicos, bem como para que pudessem propor respostas capazes de reconfigurar o quadro institucional no ensino de graduação.

As turmas de 2007 foram constituídas por docentes do campus da capital de modo interdisciplinar com a intenção de se promover a interação, as trocas de experiências, os cruzamentos dos distintos olhares a respeito de como ensinar e como aprender na universidade e também de como organizar os espaços para tanto. Os participantes foram agrupados em duas turmas: uma constituída por docentes que exerciam atividades de coordenação pedagógica dos cursos de graduação e a outra por docentes que promoviam 
ações de formação para outros docentes em suas unidades e participavam dos GAPs locais.

Em 2008, outras três turmas foram constituídas com os mesmos objetivos, sendo duas no campus da capital, com os coordenadores e organizadores dos cursos de graduação, e outra aberta a docentes sem qualquer distinção de responsabilidade ou inserção na Universidade. Uma terceira foi constituída em um campus do interior para atender aos docentes de vários outros campi, considerando as dificuldades de locomoção, distantes entre 250 a $400 \mathrm{~km}$ da capital. Em 2009, foram novamente constituídas três turmas, sendo duas na capital e uma no interior.

Os cursos tiveram como foco central estimular o desenvolvimento de intervenções no cotidiano, visando efetivar o papel da pedagogia no ensino superior e compreender, renovar e valorizar o seu lugar nas práticas de coordenação pedagógica e de atuação docente nos contextos institucionais, a partir de diagnóstico efetivado com os grupos de trabalho.

As análises teóricas que vêm sendo construídas no campo da docência no ensino superior apontam que raramente se exigiu dos docentes que aprendessem a ensinar e, menos ainda, que obtivessem referências para aprender a lidar com os processos pedagógicos e organizacionais mais amplos do ensino superior. Apesar de contar em sua estrutura acadêmica com um sistema de coordenação de cursos, a universidade em estudo nunca exigiu de seus coordenadores uma formação que resultasse em compromissos e competências para promoverem ações formativas com seus pares.

Os temas e as abordagens que então adotamos no Programa foram escolhidos com a expectativa de superar esse quadro crônico de ausência de formação para o ensino na universidade. De modo geral, foram os seguintes: conhecer a constituição histórica da universidade com vistas a compreender seus determinantes nas formas de organização curricular e de atuação docente; os fundamentos legais da educação no país; os fundamentos teóricos de Projeto Político-Pedagógico e a análise dos projetos em curso na universidade; concepções de ensino e aprendizagem e análise das praticadas na instituição; trabalho coletivo e construção de novos modelos de organização curricular com perspectivas interdisciplinares, superando a concepção fragmentária de grade de disciplinas; identidade e 
profissionalização docente; concepções de ciência, de saber, de didática e de saber escolar; conteúdo-forma (método) nos processos de ensino; ensino com pesquisa e pesquisa no ensino; critérios para seleção e organização dos conhecimentos a serem desenvolvidos; gestão do conhecimento e da informação na relação teoria-prática; finalidades do curso e do ensino; avaliação; construção de ambientes de aprendizagem nos cursos; efetivação do contrato didático entre docentes e discentes; ensino e autonomia discente; atuação profissional; perfil dos estudantes na atualidade; dentre outros.

Embora os conteúdos propostos para as turmas fossem os mesmos, as abordagens tiveram enfoques distintos. Com as turmas de coordenadores de curso, os aspectos relativos à dimensão coletiva do trabalho de ensino na universidade foram tratados com maior ênfase, pois a intenção era desenvolver as capacidades de descrever, analisar e compreender as realidades dos diferentes cursos que lhes cabe coordenarem, de modo a desenvolver competências para tratar da elaboração e/ou revisão do projeto pedagógico de curso, da articulação disciplinar das ações integradoras, da avaliação do curso como construção coletiva. Com as turmas dos integrantes dos GAPs e nas compostas por docentes interessados nas questões de ensino, as abordagens centraram-se mais na atuação pedagógica conjunta e coletiva, na identificação dos elementos constitutivos dos processos de ensino e de aprendizagem, na contextualização das práticas, nas abordagens favorecedoras do desenvolvimento da autonomia dos estudantes, da construção da identidade docente e dos processos de profissionalização.

Do ponto de vista metodológico, buscou-se trabalhar a partir das concepções prévias dos participantes, por se entender que, com os embates coletivos e com as análises das práticas a partir de novas teorias, pode-se chegar à superação das crenças anteriormente estabelecidas e à construção de novos referenciais teórico-práticos. Estratégias de estudo e discussão de textos, vídeos, relatos e análise de experiências no ensino de graduação, construção de novas propostas, atividades individuais e grupais de sínteses, resumos, resenhas, organização de quadros comparativos, esquemas, mapas conceituais, entre outras, compuseram as atividades dos participantes.

Um dos resultados dessa política de formação foi o apoio financeiro à participação dos docentes que tiveram artigos e papers aprovados para serem apresentados em eventos nacionais e internacionais classificados 
como de referência pelas agências de fomento, com foco nos aspectos relativos aos processos de organização e desenvolvimento do ensino e da aprendizagem.

Além dessa valorização pessoal/profissional dos docentes participantes, outro importante resultado foi a contribuição institucional dos docentes coordenadores e dos membros dos GAPs ao novo Regimento da Graduação, que à época encontrava-se em elaboração. Os coordenadores de cursos que participaram das atividades do Programa em 2007 redigiram as partes referentes às competências das Comissões Coordenadoras de Curso e à concepção de currículo que constam do novo regimento do ensino de graduação. Essas elaborações evidenciam a contribuição das teorias pedagógicas críticas ao novo regimento. No que se refere às competências das Comissões, por exemplo, destacam-se como contribuições inovadoras em relação ao que se praticava: coordenar a implementação e a avaliação do projeto político-pedagógico dos cursos, considerando a Lei de Diretrizes e Bases da Educação Nacional e as Diretrizes Curriculares para os Cursos de Graduação vigentes no país; encaminhar propostas de reestruturação do projeto político-pedagógico e da respectiva estrutura curricular (disciplinas, módulos ou eixos temáticos) aos órgãos deliberativos; analisar a pertinência do conteúdo programático e da carga horária de disciplinas, módulos ou eixos temáticos, de acordo com o projeto político-pedagógico, propondo alterações; promover a articulação entre os docentes envolvidos no curso ou habilitação, com vistas à integração interdisciplinar ou interdepartamental na implementação das propostas curriculares; e acompanhar a progressão dos alunos durante o curso ou habilitação, propondo ações voltadas à prática docente ou à implementação curricular.

No que se refere à concepção de currículo, a redação do coletivo dos coordenadores evidencia mais fortemente as transformações decorrentes dos Cursos de Pedagogia Universitária neles provocadas. No Regimento antigo, praticado desde a criação da USP, em 1934, sequer se mencionava currículo e a organização do ensino se dava por disciplinas. No novo Regimento, a organização do ensino pode ocorrer na forma de disciplinas, módulos ou eixos temáticos, conforme a estrutura curricular adotada, em consonância com o projeto político-pedagógico do curso. Disciplina passa a ser entendida como uma unidade curricular que organiza um conjunto de conhecimentos de uma 
área específica, definida de acordo com o projeto político-pedagógico do curso. Módulo é uma unidade curricular que articula diferentes conjuntos de conhecimentos de áreas afins, numa perspectiva interdisciplinar, definido de acordo com o projeto político-pedagógico do curso. Eixo temático é uma unidade curricular que corresponde a um ou mais módulos e abrange um bloco organizado de áreas específicas afins; compreende as atividades teóricas e práticas relativas a um assunto ou tema, permitindo a integração em diversos níveis. É relevante destacar que o novo não necessariamente invalida o antigo. Ao manter disciplina, estabelece-se um diálogo com o existente, mas se introduz definida conforme o projeto político-pedagógico (antes ausente) e se abre para novas formas de organização curricular interdisciplinares e mesmo transdisciplinares com a organização dos cursos em Módulos e/ou Eixos Temáticos. É importante ressaltar ainda que essas modalidades curriculares já vinham sendo experimentadas por alguns cursos, que enfrentavam fortes resistências institucionais, especialmente para conseguir ampliar seu quadro docente, fortemente vinculado à disciplina.

Outro resultado importante da política desenvolvida foi a institucionalização, em 2009, dos GAPs, que tinham até então um estatuto frágil assentado na boa vontade e no interesse de alguns professores de algumas (poucas) unidades da Universidade. O GAP Central passou a ter o estatuto de uma dentre as Comissões Assessoras do Conselho de Graduação (CoG), com a nova sigla CAP - Comissão de Apoio Pedagógico, tendo por competências: assessorar o CoG, suas Câmaras e a Pró-Reitoria de Graduação na elaboração e implementação da política de aperfeiçoamento pedagógico do corpo docente da Universidade e em assuntos relativos ao aperfeiçoamento pedagógico dos docentes e dos cursos; favorecer a troca de experiências pedagógicas entre os docentes; e incentivar e desenvolver pesquisas sobre temáticas relativas à Pedagogia Universitária.

\section{Demandas e contribuições ao campo teórico da docência universitária}

Análise preliminar da implantação dessa política nos permite evidenciar alguns pontos a serem considerados com vistas ao desenvolvimento e enraizamento de políticas institucionais de formação pedagógica de docentes universitários. Um primeiro ponto que merece 
destaque é a importância atribuída à formação. Para que a mobilização institucional surta efeito, coloca-se como fundamental que se priorize essa formação nas definições orçamentárias e organizacionais, de modo a assegurar a estabilidade dessa política. No caso estudado, são evidentes as condições institucionais favoráveis para essa formação docente: a criação de uma estrutura que foi especialmente reorientada para cuidar da formação pedagógica dos docentes e exercer a coordenação específica das ações em curso (a CAP); a presença de assessor acadêmico especializado na área e de funcionários; e a disponibilidade de recursos financeiros suficientes para implementar a formação aos docentes interessados. Essas são condições indispensáveis para a implementação dessa formação, evidenciando a disposição política das instituições.

Um segundo ponto refere-se à diversidade de linhas de formação. As ações desenvolvidas foram aglutinadas em três grandes eixos: as voltadas para o atendimento de demandas ou necessidades dos professores a serem contempladas por aqueles que se dispõem a favorecer situações formativas com os pares nas unidades acadêmicas (os integrantes dos GAPs, no caso); as que se desenvolvem a partir das demandas postas pelas ações de coordenação dos cursos; e as vividas pelos docentes em sala de aula. A partir dessas três linhas de trabalho, foram se produzindo distintos tipos de conhecimentos a respeito das ações institucionais dos participantes.

O terceiro ponto refere-se às ações formativas que buscam constituir as bases para um novo modelo de formação universitária. Os esforços nesse sentido foram as ações voltadas para possibilitar uma mudança nos objetivos do trabalho docente, à medida que os subsídios foram orientados para que a organização da prática do ensino não mais estivesse assentada na transmissão de conhecimentos, mas na interação entre professor/aluno/ conhecimento, fazendo da pesquisa uma referência para a formação dos estudantes universitários, futuros profissionais. Outro exemplo foram os esforços para entender a organização dos cursos como resultado da articulação pedagógica entre os campos disciplinares, expressa num projeto político-pedagógico institucional, fruto de decisões colegiadas (as Comissões de Graduação e/ou Coordenações de Cursos, no caso). Assim, as temáticas e os métodos de trabalho integrativo com docentes de várias unidades e áreas do conhecimento possibilitaram que os cursos desenvolvessem 
perspectivas interdisciplinares na produção de conhecimentos sobre a própria universidade e sobre o ensinar e o aprender. Em síntese, buscou-se efetivar o papel da pedagogia nas práticas de coordenação pedagógica e na atuação docente.

Um quarto ponto refere-se à aposta na dimensão coletiva da formação docente. O modo como o trabalho formativo nos cursos foi sendo desenvolvido priorizou a produção, a contextualização e a análise de experiências dos docentes de modo a que pudessem ser compreendidas e trabalhadas por todos. Com isso, também foi possível: valorizar a tolerância no trabalho coletivo, a capacidade de escuta e de interação, a sensibilidade para questionar os outros e a si próprio; estabelecer relações de confiança profissional e parceria; e instalar um clima que pudesse favorecer as trocas e o diálogo entre os participantes. Desenvolveu-se, então, com maior facilidade, a compreensão de que os percursos formativos e de desenvolvimento profissional são processos vividos coletivamente e estão associados a situações de intercâmbio frequente.

De modo geral, percebe-se, à semelhança do que ocorreu no caso, que os docentes participantes, ao vivenciarem um processo formativo que se soma às bases da docência anteriormente constituídas, tornam-se mais preparados para considerarem, numa perspectiva crítica, os contextos histórico, social, cultural e organizacional onde realizam suas práticas. Contribui também, para isso, o trabalho sustentado em estratégias capazes de promover a permanente construção da identidade de professor e para a consolidação das bases conceituais que sustentam as atividades inerentes ao ensino.

\section{Notas}

1 A USP, fundada em 1934, é uma universidade pública e gratuita situada no estado de São Paulo, região Sudeste do Brasil. Conta com cerca de 60 mil estudantes de graduação, em seus 242 cursos de todas as áreas do conhecimento, e cerca de 30 mil em pós-graduação (mestrado e doutorado), e com 6 mil docentes e 20 mil funcionários, aproximadamente. Seu campus principal está situado na capital do estado de São Paulo e os demais campi (7) estão situados em municípios do interior desse mesmo estado. 
2 De ampliação de vagas e de inclusão social para ampliar o acesso dos segmentos menos favorecidos da sociedade em seus cursos, o que colocaria desafios até então desconhecidos aos docentes, em suas atividades de ensino na graduação, com a presença de estudantes com perfil diferente do que estavam habituados.

\section{Referências}

Alarcão, I. (2003). Professores reflexivos em uma escola reflexiva. São Paulo: Cortez Editora.

Almeida, M. I. (2012). Formação do professor do ensino superior. São Paulo: Cortez Editora.

Almeida, M. I. (1999). Os professores diante das reformas educacionais. In M. A. Bicudo \& C. A. Silva (Org), Formação do educador e avaliação educacional - Vol. 3. (pp. 249-261). São Paulo: Ed. UNESP.

Almeida, M. I. (2006). Apontamentos a respeito da formação de professores. In R. L. L. Barbosa (Org.), Formação de educadores: Artes e técnicas - ciências e políticas (pp. 177-188). São Paulo: Edunesp.

Anastasiou, L. G. C. (2011). Processos formativos de docentes universitários: Aspectos teóricos e práticos. In S. G. Pimenta \& M. I. Almeida (Orgs.), Pedagogia universitária - Caminhos para a formação de professores (pp. 44-74). São Paulo: Cortez Editora.

Araújo, K. (2005). Os saberes docentes dos professores iniciantes no ensino superior: Um estudo na Universidade Federal de Pernambuco (Dissertação de Mestrado). Universidade Federal de Pernambuco, Recife.

Belletati, V. C. F. (2011). Dificuldades de alunos ingressantes na universidade pública: Um ponto de partida para reflexões sobre a docência universitária (Tese de doutorado). Faculdade de Educação da Universidade de São Paulo, São Paulo.

Benedito, V., Ferrer, V., \& Ferreres, V. (1995). La formación universitaria a debate: Análisis de problemas y planteamiento de propuestas para la docencia y la formación del profesorado universitario. Barcelona: Universitat de Barcelona.

Biggs, J. (2006). Cambiar la enseñanza universitaria. In J. Biggs, Calidad del aprendizaje universitario (pp. 19-53). Madrid: Narcea.

Brezinski, I. (2002). Docência universitária e sucesso acadêmico - Um olhar brasileiro. In J. Tavares (Org.), Pedagogia universitária e sucesso académico (pp. 17-31). Aveiro: Universidade de Aveiro.

Corrêa, A. K. (2011). Formação pedagógica do professor universitário: Reflexões a partir de uma experiência. In S. G. Pimenta \& M. I. Almeida (Orgs.), Pedagogia universitária - Caminhos para a formação de professores (pp. 75-100). São Paulo: Cortez Editora.

Creten, S., \& Huyghe, S. (2013). Teaching at the University of Leuven: A case of teacher training in higher education in Flanders, Belgium. Revista de Docencia Universitaria, 11(30), 73-90. 
Cunha, M. I. (1998). O professor universitário na transição de paradigmas. Araraquara: JM Editora.

Cunha, M. I. (2006). Docência na universidade, cultura e avaliação institucional: Saberes silenciados em questão. Revista Brasileira de Educação, 11(32), 258271.

Cunha, M. I. (2009). O lugar da formação do professor universitário: O espaço da pósgraduação em educação em questão. Revista Diálogo Educacional, 9(26), 81 90.

Debry, M., Leclercq, D., \& Boxus, E. (1998). De nouveaux défis pour la pédagogie universitaire. In D. Leclercq (Ed.), Pour une pédagogie universitaire de qualité (pp. 55-80). Sprimont: Mardaga.

Dias, A. M., \& Ketzer, S. M. (Org.). (2007). Memória do ForGRAD - 20 anos do Fórum Nacional de Pró-Reitores de Graduação das Universidades Brasileiras. Porto Alegre: EDIPUCRS.

Dipietro, M., \& Buddie, A. M. (2013). Graduate teacher training in the U.S.: Snapshots from the landscape. Revista de Docencia Universitaria, 11(3), 41-52.

Faria, L. R. (2011). As orientações educativas contra-hegemônicas das décadas de 1980 e 1990 e os rebatimentos pós-modernos nas recentes produções acadêmicas da área da didática (Tese de doutorado). Faculdade de Educação da Universidade de São Paulo, São Paulo.

Feixas, M. (2004). La influencia de factores personales, institucionales y contextuales en la trayectoria y el desarrollo docente de los profesores universitarios. Educar, 33, 31-59.

Fernández, A. (1999). La formación didáctica del profesorado universitario: Qué hemos aprendido en los últimos 10 años? In La calidad de la docencia universitaria. Actas del II Simposio Iberoamericano de Didáctica Universitaria. Santiago: Universidad de Santiago.

Fiorentini, D., \& Souza e Melo, G. F. (1998). Saberes docentes: Um desafio para acadêmicos e práticos. In C. Geraldi (Org), Cartografias do trabalho docente: Professor(a)-pesquisador(a) (pp. 307-335). Campinas: Mercado das Letras.

Flores, M. A. (2007). Perspectivas e estratégias de formação de docentes do ensino superior. Um estudo na Universidade do Minho. Braga: CIEd, Universidade do Minho.

Freire, P. (2011). Pedagogia da autonomia - Saberes necessários à prática pedagógica (43 ${ }^{a}$ ed.). São Paulo: Editora Paz e Terra.

Gibbs, G. (2004). Mejorar la enseñanza y el aprendizaje universitario mediante estrategias institucionales. Educar, 33, 11-26.

Kato, K. (2013). University teacher training in Japan. Revista de Docencia Universitaria, $11(3), 53-63$.

Leite, C., \& Ramos, K. (2012). Formação para a docência universitária: Uma reflexão sobre o desafio de humanizar a cultura científica. Revista Portuguesa de Educação, 25(1), 7-27.

Leite, D. (1999). Pedagogia universitária. Porto Alegre: Editora UFRS. 
Masetto, M. (2004). Inovação na educação superior. Interface comunicação, saúde, educação, 8(14), 197-203.

Morin, E. (2000). Complexidade e transdisciplinaridade $-A$ reforma da universidade $e$ do ensino fundamental. Natal: EDUFRN.

Nóvoa, A. (2013). Universidade. In J. Cardoso, P. Magalhães \& J. Machado Pais (Orgs.), Portugal social de $A$ a $Z$ (pp. 261-270). Paço de Arcos: Impresa Publishing/Expresso.

Pimenta, S. G., \& Anastasiou, L. G. (2002). Docência no ensino superior. São Paulo: Cortez Editora.

Pimenta, S. G., Almeida, M. I., \& Oliveira, M. A. (2010). A graduação na Universidade de São Paulo: Análise de uma gestão. São Paulo: Edição Pró-Reitoria de Graduação, Universidade de São Paulo (CD ROM).

Rios, T. A. (2009). Ética na docência universitária - Apontamentos para um diálogo. In M. I. Cunha, S. R. Soares \& M. L. Ribeiro (Orgs.), Docência universitária: Profissionalização e práticas educativas (pp. 117-130). Feira de Santana: UEFS Editora.

Rué, J. (2007). Enseñar en la universidad - El EEES como reto para la educación superior. Madrid: Narcea.

Rué, J., Arana, A., González, M., Abadía, A. R., Blanco, F., Bueno, C., \& Fernández, A. (2013). El desarrollo docente en España en educación superior: El optimismo de la voluntad en un modelo de caja negra. Revista de Docencia Universitaria, 11(3), 125-158.

Veiga, I. P., \& Castanho, M. E. L. (2000). Pedagogia universitária - A aula em foco. Campinas, SP: Papirus.

Zabalza, M. A. (2004). O ensino universitário. Seu cenário e seus protagonistas. Porto Alegre: Artmed. 


\section{UNIVERSITY PEDAGOGY - VALUING EDUCATION AND TEACHING AT UNIVERSITY}

\section{Abstract}

How and under what circumstances training processes regarding how to be a teacher can be developed at a complex university? The paper suggests possible answers to this question, from analysis of the establishment of a teacher education policy at a public university - University of São Paulo, Brazil - whose tradition of research activities overlaps with teaching. To broaden understanding of the undertaken experience, it discusses the meaning of higher education in the context of contemporary university crisis and analyses experiences in institutions that point the importance of teachers to ensure the social significance of university. The analysis is supported by written records and research produced by participants of the process (teachers, managers, doctoral students) as instruments. Considering a conceptual framework of university teaching, the results show some contributions to the field: importance of institutional rooting of policies for pedagogical education of university teachers; inclusion of these policies in the institutional budget; diversity of these educational activities; and enhancement of research findings of teachers about teaching.

\section{Keywords}

Teaching and research; University; Institutional policy 


\title{
PÉDAGOGIE UNIVERSITAIRE - VALORISANT L'ENSEIGNEMENT ET L'ACTE D'ENSEIGNER À L'UNIVERSITÉ
}

\begin{abstract}
Résumé
Comment et dans quelles circonstances les processus de formation concernant le "savoir être" enseignant peuvent être développés au sein d'une université complexe? Ce texte propose quelques réponses possibles à cette question, à partir de l'analyse de la constitution d'une politique de formation d'enseignants au sein d'une université publique - I'Université de São Paulo, Brésil - dont la tradition privilégie la recherche en dépit de l'enseignement. Pour mieux comprendre l'expérience réalisée, nous discutons le sens des cursus de licence dans le cadre de la crise de l'université contemporaine et analysons plusieurs expériences institutionnelles qui indiquent l'importance des enseignants pour assurer le rôle social de l'université. Les notes prises et les recherches réalisées par les participants du processus (professeurs, gestionnaires, doctorants) sont à la base de cette étude. Considérant le cadre théorique et conceptuel de l'enseignement à l'université, les résultats de l'analyse apportent quelques contributions à ce domaine: l'enracinement institutionnel des politiques de formation pédagogique des enseignants universitaires; I'inclusion de cette formation dans le budget de l'université; la diversité des actions formatives; et la valorisation de la production scientifique des professeurs sur l'enseignement.
\end{abstract}

Mots-clé

Enseignement et recherche; cursus de licence; Université; Politique institutionnelle

Recebido em maio/2014

Aceite para publicação em outubro/2014

Faculdade de Educação, Universidade de São Paulo, Brasil

ii Faculdade de Educação, Universidade de São Paulo, Brasil

Toda a correspondência relativa a este artigo deve ser enviada para: Selma Garrido Pimenta, Rua Maranhão, 107 - apto. 202, 01240 - 001 São Paulo - SP, Brasil. E-mail: sgpiment@usp.br 